\title{
Guidelines adherence in the prevention and management of chronic kidney disease in patients with diabetes mellitus on the background of recent European recommendations - a registry-based analysis
}

Peter Bramlage ${ }^{1 *}$, Stefanie Lanzinger ${ }^{2,3}$, Sascha R. Tittel ${ }^{2,3}$, Eva Hess ${ }^{4}$, Simon Fahrner ${ }^{5}$, Christoph H. J. Heyer ${ }^{6}$, Mathias Friebe ${ }^{7}$, Ivo Buschmann ${ }^{8,9}$, Thomas Danne ${ }^{10}$, Jochen Seufert ${ }^{11}$ and Reinhard W. Holl ${ }^{2,3}$

\begin{abstract}
Background: Recent European Society of Cardiology (ESC)/European Association for the Study of Diabetes (EASD) guidelines provide recommendations for detecting and treating chronic kidney disease (CKD) in diabetic patients. We compared clinical practice with guidelines to determine areas for improvement.

Methods: German database analysis of 675,628 patients with type 1 or type 2 diabetes, with 134,395 included in this analysis. Data were compared with ESC/EASD recommendations.

Results: This analysis included 17,649 and 116,747 patients with type 1 and type 2 diabetes, respectively. The analysis showed that 44.1 and $49.1 \%$ patients with type 1 and type 2 diabetes, respectively, were annually screened for CKD. Despite anti-diabetic treatment, only $27.2 \%$ patients with type 1 and $43.5 \%$ patients with type 2 achieved a target $\mathrm{HbA} 1 \mathrm{c}$ of $<7.0 \%$. Use of sodium-glucose transport protein 2 inhibitors ( $1.5 \%$ type $1 / 8.7 \%$ type 2 diabetes) and glucagon-like peptide-1 receptor agonists (0.6\% type 1/5.2\% type 2 diabetes) was limited. Hypertension was controlled according to guidelines in 41.1 and $67.7 \%$ patients aged 18-65 years with type 1 and 2 diabetes, respectively, (62.4 vs. $68.4 \%$ in patients $>65$ years). Renin angiotensin aldosterone inhibitors were used in 24.0 and $40.9 \%$ patients with type 1 diabetes (micro- vs. macroalbuminuria) and 39.9 and $47.7 \%$, respectively, in type 2 diabetes.

Conclusions: Data indicate there is room for improvement in caring for diabetic patients with respect to renal disease diagnosis and treatment. While specific and potentially clinically justified reasons for non-compliance exist, the data may serve well for a critical appraisal of clinical practice decisions.
\end{abstract}

Keywords: diabetes, hypertension, chronic kidney disease, glomerular filtration rate, albuminuria, diagnostics, pharmacotherapy

\footnotetext{
* Correspondence: peter.bramlage@ippmed.de

${ }^{1}$ Institute for Pharmacology and Preventive Medicine, Bahnhofstrasse 20, 49661 Cloppenburg, Germany

Full list of author information is available at the end of the article
}

(c) The Author(s). 2021 Open Access This article is licensed under a Creative Commons Attribution 4.0 International License, which permits use, sharing, adaptation, distribution and reproduction in any medium or format, as long as you give appropriate credit to the original author(s) and the source, provide a link to the Creative Commons licence, and indicate if changes were made. The images or other third party material in this article are included in the article's Creative Commons licence, unless indicated otherwise in a credit line to the material. If material is not included in the article's Creative Commons licence and your intended use is not permitted by statutory regulation or exceeds the permitted use, you will need to obtain permission directly from the copyright holder. To view a copy of this licence, visit http://creativecommons.org/licenses/by/4.0/. The Creative Commons Public Domain Dedication waiver (http://creativecommons.org/publicdomain/zero/1.0/) applies to the data made available in this article, unless otherwise stated in a credit line to the data. 


\section{Background}

Early detection and treatment of chronic kidney disease (CKD) in patients with diabetes may prevent or delay the development of end-stage renal disease (ESRD), as well as subsequent morbidity and mortality. The Kidney Disease Outcomes Quality Initiative (KDOQI) of the National Kidney Foundation has recommended the use of estimating equations for glomerular filtration rate (GFR) on the basis of serum creatinine determinations and urinary albuminto-creatinine ratio (UACR) since 2011 [1, 2].

Screening recommendations are essentially unaltered since 2011 [3, 4]. The 2019 guidelines of the European Society of Cardiology (ESC)/European Association for the Study of Diabetes (EASD) [3] recommend that patients with chronic kidney disease undergo annual spot UACR, serum creatinine and estimated GFR (eGFR) evaluations (recommendation class I, level of evidence A) along with a number of specific recommendations for the treatment of affected patients. Particular attention must be given to tight glucose and blood pressure control: It is recommended to target an $\mathrm{HbA1c}<7.0 \%$ (or $<53 \mathrm{mmol} / \mathrm{mol}$ ) to decrease microvascular complications (recommendation class I, level of evidence A). Blood pressure should be lowered to $130 \mathrm{mmHg}$ systolic blood pressure (SBP) or lower (but not $<120 \mathrm{mmHg}$ ), while a SBP between 130 and $139 \mathrm{mmHg}$ is recommended for patients $>65$ years (recommendation class I, level of evidence A). Diabetic patients with hypertension should be treated with reninangiotensin-aldosterone system (RAAS)-blocking agents (angiotensin converting enzyme inhibitor [ACEi]/angiotensin receptor blocker [ARBs]) especially when microalbuminuria, macroalbuminuria/proteinuria, or left ventricular hypertrophy $(\mathrm{LVH})$ is present (recommendation class I, level of evidence A). Treatment with sodiumglucose transport protein 2 inhibitors ([SGLT-2i] empagliflozin, canagliflozin, or dapagliflozin) is advised in patients with an eGFR 30 to $<90 \mathrm{~mL} / \mathrm{min} / 1.73 \mathrm{~m}^{2}$ ) (recommendation class I, level of evidence B) and glucagon-like peptide-1 receptor agonist ([GLP-1Ras] liraglutide, semaglutide) in patients if eGFR is $>30 \mathrm{~mL} / \mathrm{min} / 1.73 \mathrm{~m}^{2}$ (recommendation class IIa, level of evidence B).

The aim of our study, using a large combined database of 675,628 patients with diabetes treated in Germany, [5, 6] was to determine rates of adherence to treatment guidelines, gain a better understanding of the medications used to treat diabetes in Germany, determine areas for the improvement in the screening of diabetic patients, and assess the use of potentially beneficial treatment strategies.

\section{Methods}

\section{Study design and data sources}

This analysis used combined data from the Diabetes Patienten Verlaufsdokumentation (DPV) and Diabetes
Versorgungsevaluation (DIVE) registries. Their design has been described previously [7-9]. In short, the DPV initiative collects data on patients with diabetes mellitus from centres predominantly in Germany. The diagnosis of diabetes type, selection of medication used, types of assessment conducted, and information recorded in the database are made by the patient's clinician. Data are collected every 6 months using DPV software and the anonymized data are sent to the University of Ulm for aggregation into the database. The DPV initiative was established in 1995, approved by the University of Ulm ethics committee, and data collection approved by local review boards. The DIVE registry was established in 2011. Consecutive patients with diabetes mellitus, regardless of their disease stage, were enrolled from centres across the country, and continue to be followed up. The DIVE protocol was approved by the ethics committee of the Medical School of Hannover, and all patients included in the DIVE registry provided written informed consent.

\section{Patient selection}

From a total of 144 DIVE and 503 DPV centres from Germany, 416 were included in the present analysis based on their provision of patient data eligible for the analysis (Fig. 1). The last patient considered for this analysis was from September 2020. They were included in the current analysis if they had type 1 or type 2 diabetes, were at least 18 years old, and were confined to those whose details were first entered in the database between 2015 and 2020, and had HbA1c information available.

\section{Definitions}

GFR was estimated based on the Chronic Kidney Disease Epidemiology Collaboration (CKD-EPI) formula. Microalbuminuria was defined as an UACR between 30 and $300 \mathrm{mg} / \mathrm{g}$ or an albumin excretion of 30 to $300 \mathrm{mg} /$ $\mathrm{L}$, macroalbuminuria/proteinuria as an UACR of at least $300 \mathrm{mg} / \mathrm{g}$ or an albumin excretion of at least $300 \mathrm{mg} / \mathrm{L}$. CKD was defined as either an eGFR $<60 \mathrm{ml} / \mathrm{min} / 1.73$ $\mathrm{m}^{2}$ and/or at least microalbuminuria and/or kidney transplantation/dialysis. Hypertension was defined as an $\mathrm{SBP}>130 \mathrm{mmHg}$ systolic in patients $\leq 65$ years and $>$ $140 \mathrm{mmHg}$ in patients $>65$ years and/or antihypertensive treatment. Controlled hypertension was defined as a blood pressure $\leq 130 \mathrm{mmHg}$ but not below $120 \mathrm{mmHg}$ in patients $\leq 65$ years and a blood pressure 130-139 $\mathrm{mmHg}$ in patients $>65$ years.

\section{Statistics}

Data from all patients were combined and analyzed as a single data set. Categorical variables are presented as percentages. Continuous variables are presented as means with standard deviations. Patient characteristics were described by the type of diabetes. Estimates for the proportion of patients (\%) reported in Figs. 1, 2, 3, 4, 5, 6 and 7 


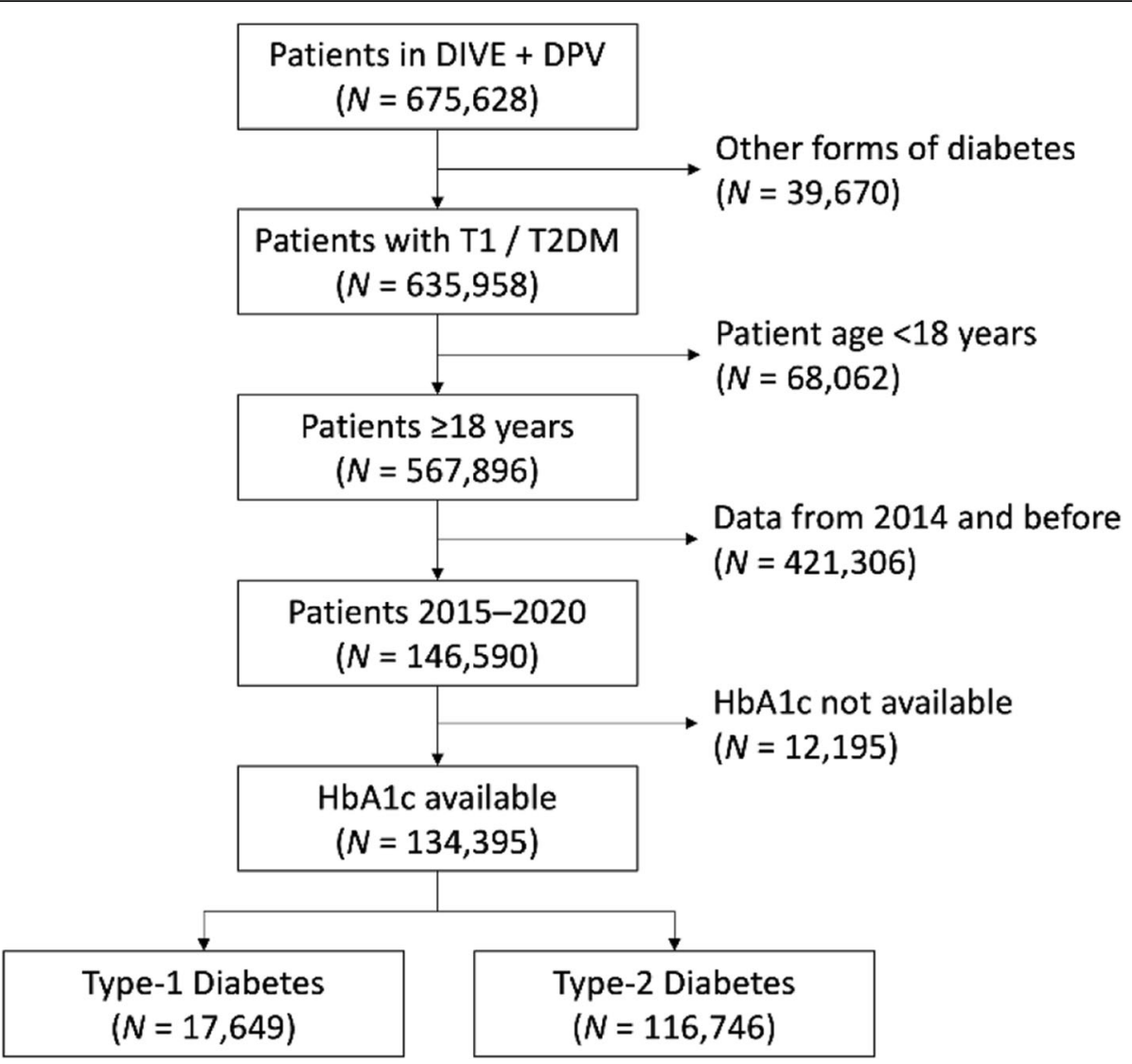

Fig. 1 Patient population

were provided together with $95 \%$ confidence intervals (CI) for the last treatment year. Statistical analysis was performed using Statistical Analysis System, version 9.4 (SAS, North Carolina, USA).

\section{Results}

The dataset comprised 675,978 patients (Fig. 1), of which 134,395 had either type 1 or type 2 diabetes, were 18 years or older, had in- or outpatient visits between 2015 and 2020 and at least one HbA1c value available. Of these, 17,649 had type 1 and 116,746 had type 2 diabetes.

\section{Patient characteristics}

Patients with type 1 diabetes (Table 1 ) had a mean age of 45.0 years, $53.7 \%$ were male, the mean diabetes duration was 15.9 years, the mean body mass index (BMI) $25.9 \mathrm{~kg} / \mathrm{m}^{2}, 11.9 \%$ had a history of cardiovascular disease and the mean $\mathrm{HbA} 1 \mathrm{c}$ was $8.3 \%(67.7 \mathrm{mmol} / \mathrm{mol})$. Their eGFR was $92.7 \mathrm{~mL} / \mathrm{min} / 1.73 \mathrm{~m}^{2}, 20.6 \% \mathrm{had}$ microalbuminuria, $5.1 \%$ macroalbuminuria and the mean serum potassium was $5.5 \mathrm{mEq} / \mathrm{L}$.

Patients with type 2 diabetes had a mean age of 67.8 years, $55.4 \%$ were male, the mean diabetes duration was
10.0 years, the mean BMI $31.3 \mathrm{~kg} / \mathrm{m}^{2}, 29.1 \%$ had a history of cardiovascular disease and the mean $\mathrm{HbAlc}$ was $7.8 \%(61.3 \mathrm{mmol} / \mathrm{mol})$. Their eGFR was $68.3 \mathrm{~mL} / \mathrm{min} /$ $1.73 \mathrm{~m}^{2}, 30.6 \%$ had microalbuminuria, $9.1 \%$ macroalbuminuria and the mean serum potassium was $5.3 \mathrm{mEq} / \mathrm{L}$.

Beyond obvious differences between patients with type 1 and type 2 diabetes such as age, BMI and duration of diabetes, patients with type 2 diabetes had a higher mean blood pressure, a higher comorbidity burden and a lower HbA1c. Differences in the eGFR were substantial with an absolute difference of $+24.4 \mathrm{~mL} / \mathrm{min} / 1.73 \mathrm{~m}^{2}$ for type 1 vs. type 2 diabetes, and an absolute difference in the rate of microalbuminuria of $-10 \%$. Drugs that are considered to have an effect on renal function were more widely prescribed in type 2 diabetes such as ACEi (22.9 vs. $10.2 \%)$, ARBs (14.0 vs. $6.2 \%)$, mineralocorticoid receptor antagonists ([MRAs] 2.5 vs. $0.5 \%$ ) and SGLT2is (9.0 vs. $1.0 \%)$.

\section{CKD screening}

The ESC/EASD guidelines recommend that patients with diabetes are screened annually for the presence of kidney disease by the assessment of eGFR and UACR 


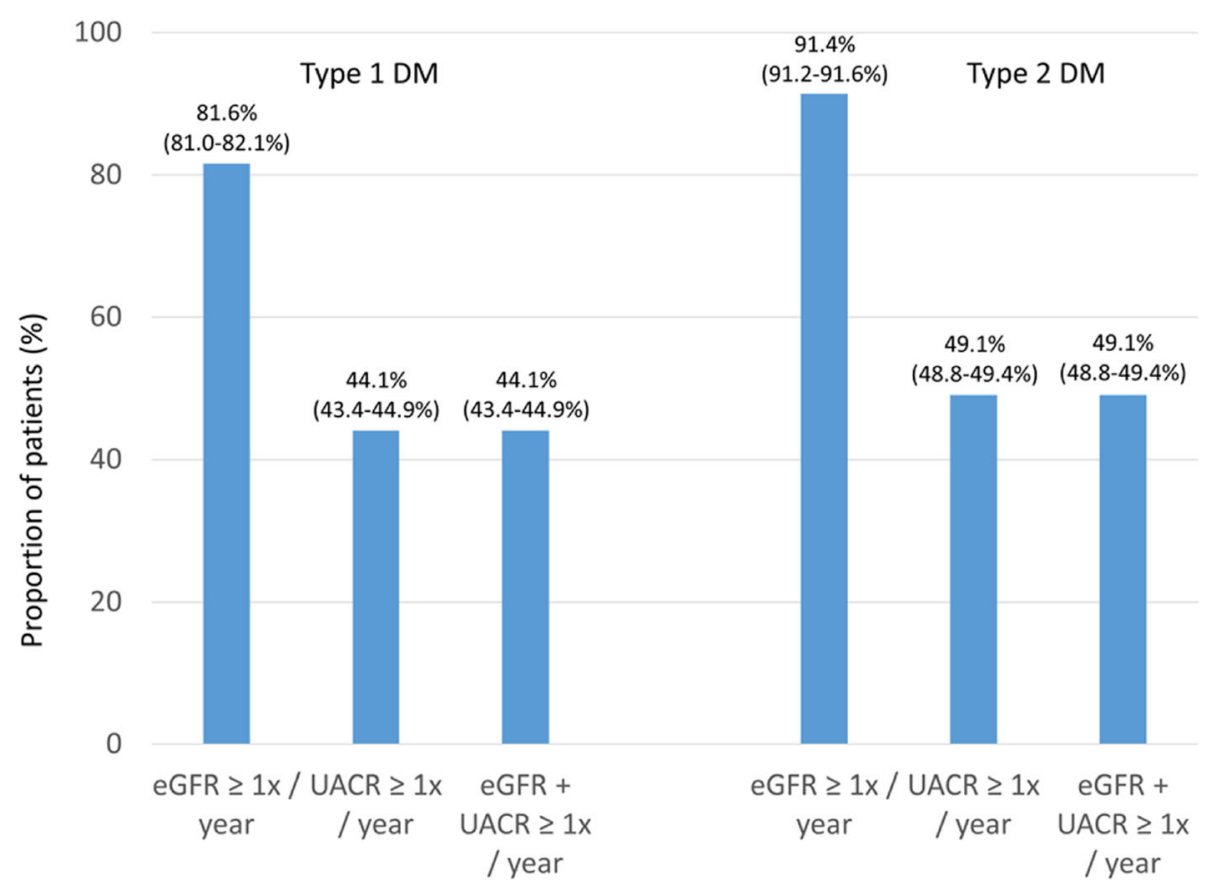

Fig. 2 Proportion of patients undergoing guideline-recommended GFR/UACR assessments. Legend: It is recommended that patients with diabetes are screened annually for kidney disease by assessment of eGFR and urinary albumin:creatinine ratio [3]. Values are percent with $95 \%$ Cls; values are from the last treatment year.

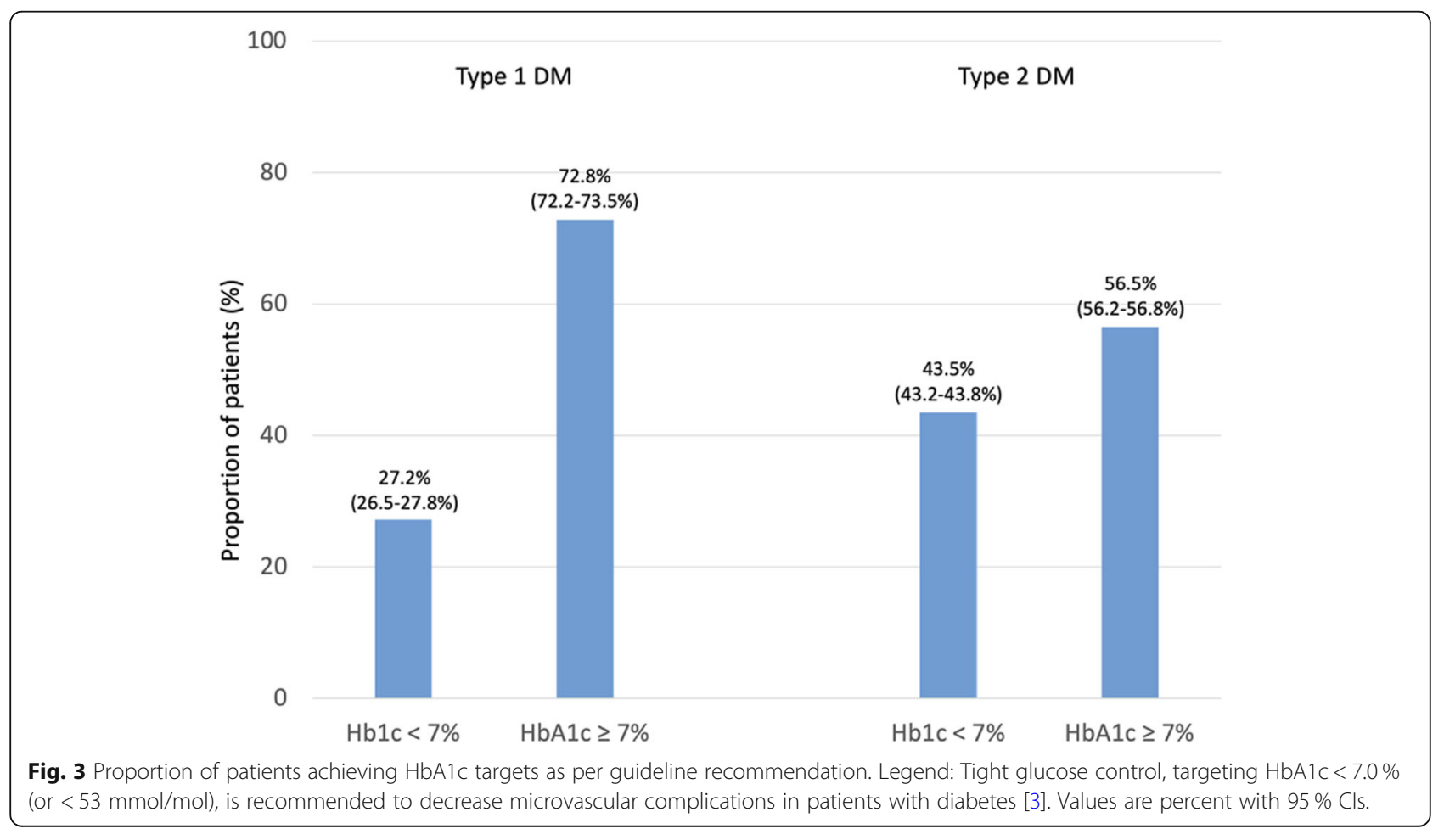




\section{5}

Type 1 DM

Type 2 DM

के

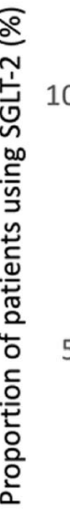

5

$90 \%$

$9.0 \%$
$(8.8-9.2 \%)$

$8.7 \%$

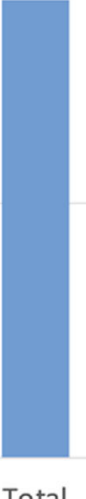

$(8.5-8.9 \%)$

0

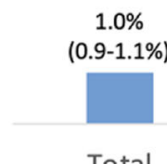

$1.5 \%$

$(1.2-1.9 \%)$

Total

eGFR $30-<90$

Total

eGFR $30-<90$

Fig. 4 Proportion of patients using SGLT-2 as per guideline recommendation. Legend: Treatment with an SGLT2 inhibitor (empagliflozin, canagliflozin or dapagliflozin) is associated with a lower risk of renal endpoints and is recommended* if eGFR is 30 to $<90 \mathrm{~mL} / \mathrm{min}^{\prime} / 1.73 \mathrm{~m}{ }^{2}$ ) [3]. Analyses restricted to the last treatment year; values are percent with $95 \% \mathrm{Cls}^{*}{ }^{*}$ Although evidence is very limited for patients with T1DM

Type 1 DM

Type 2 DM

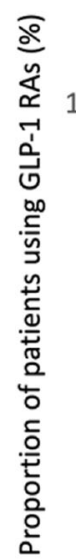
10

$6.0 \%$

(5.8-6.1\%)

$(5.2-5.5 \%)$

5
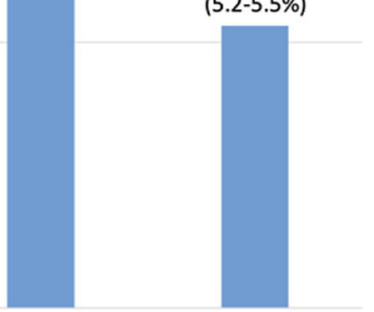

0

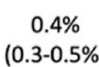

$0.6 \%$

$(0.4-0.8 \%)$

Total

eGFR $>30$

Total

eGFR $>30$

Fig. 5 Proportion of patients using GLP-1 RAs as per guideline recommendation. Legend: Treatment with the GLP1-RAs liraglutide and semaglutide is associated with a lower risk of renal endpoints, and should be considered* for DM treatment if eGFR is $>30 \mathrm{~mL} / \mathrm{min} / 1.73 \mathrm{~m}{ }^{2}$ [3]. Analyses restricted to the last treatment year; values are percent with $95 \% \mathrm{Cls}$; ${ }^{*}$ Although evidence is not available for patients with T1DM 


\section{0}

Type 1 DM

Type 2 DM

웅

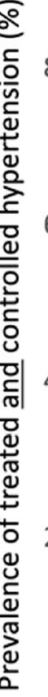

0

$\begin{array}{ccc}68.1 \% & 67.7 \% & 68.4 \% \\ (67.8-68.4 \%) & (67.2-68.1 \%) & (68.0-68.7 \%)\end{array}$

$62.4 \%$

$\begin{array}{lll}(67.8-68.4 \%) & (67.2-68.1 \%) \quad(68.0-68.7 \%)\end{array}$

60

(60.6-64.2\%)

$40.6 \%$

(43.8-45.3\%)

$41.1 \%$

(40.3-41.9\%)

40

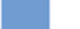

$(4-3-41.9 \%$
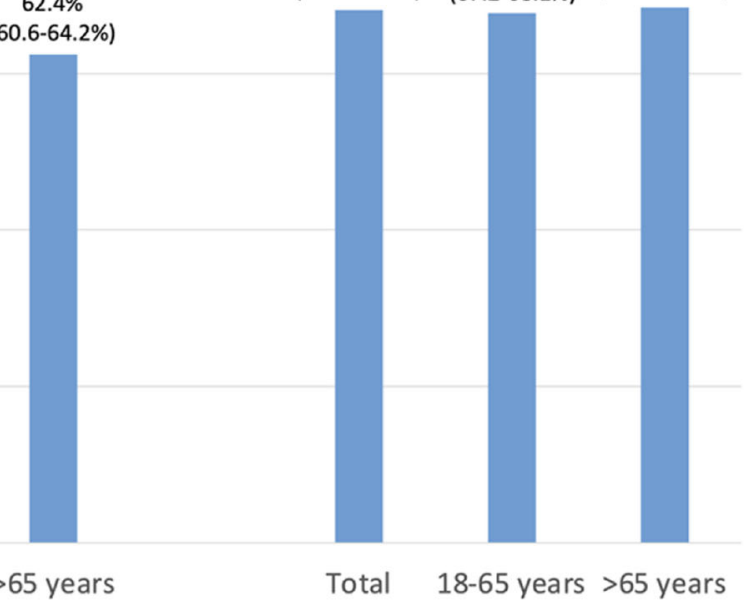

Fig. 6 Prevalence of treated and controlled hypertension. Legend: It is recommended that patients with hypertension (>130 mmHg systolic and/ or antihypertensive drug use) and diabetes are treated in an individualised manner, SBP to $130 \mathrm{mmHg}$ and $<130 \mathrm{mmHg}$ if tolerated, but not $<$ $120 \mathrm{mmHg}$. In older people (aged > 65 years) with hypertension (>140 mmHg systolic and/or antihypertensive treatment) the SBP goal is to a range of $130-139 \mathrm{mmHg}$ [3]. Values are percent with $95 \% \mathrm{Cls}$

\section{0}

Type 1 DM

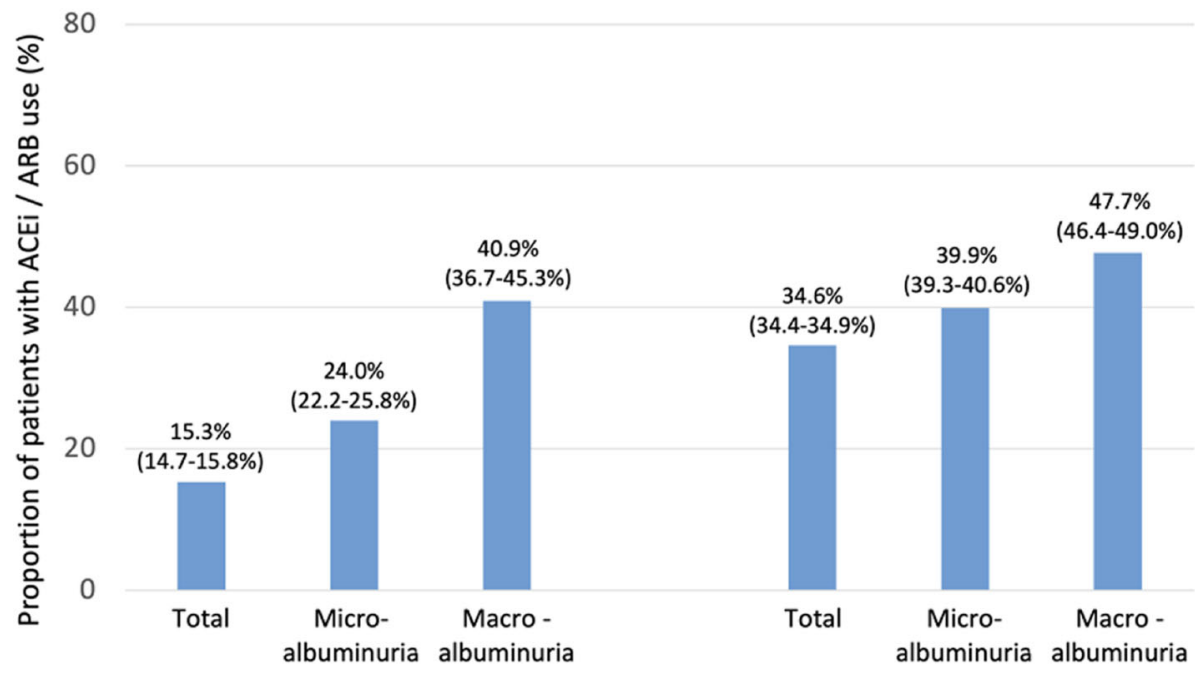

Fig. 7 Proportion of patients using ACEi/ARBs as per guideline recommendation. Legend: A RAAS blocker (ACEi or ARB) is recommended for the treatment of hypertension in patients with diabetes, particularly in the presence of microalbuminuria, proteinuria (macroalbuminuria*), or LVH** [3]. Values are percent with $95 \% \mathrm{Cls}$; *Proteinuria was replaced by macroalbuminuria as this was generally determined; **LVH is not available in the DIVE/DPV dataset 
Table 1 Patient characteristics

\begin{tabular}{|c|c|c|c|c|}
\hline & \multicolumn{2}{|c|}{ Type 1 DM $(n=17,649)$} & \multicolumn{2}{|c|}{ Type 2 DM $(n=116,746)$} \\
\hline & $\mathrm{N}$ avail & Mean \pm SD or $\%$ & $\mathrm{~N}$ avail & Mean \pm SD or $\%$ \\
\hline Age, years & 17,649 & $45.0 \pm 18.4$ & 116,746 & $67.8 \pm 13.8$ \\
\hline Gender, male & 17,649 & 53.7 & 116,746 & 55.4 \\
\hline BMl, $\mathrm{kg} / \mathrm{m}^{2}$ & 16,708 & $25.9 \pm 5.6$ & 107,490 & $31.3 \pm 7.1$ \\
\hline Duration of diabetes, years & 17,649 & $15.9 \pm 15.3$ & 116,746 & $10.0 \pm 9.4$ \\
\hline $\mathrm{HbA} 1 \mathrm{c}, \%$ & 17,649 & $8.3 \pm 2.1$ & 116,746 & $7.8 \pm 2.0$ \\
\hline $\mathrm{mmol} / \mathrm{mol}$ & 17,649 & $67.7 \pm 23.2$ & 116,746 & $61.3 \pm 22.2$ \\
\hline Systolic blood pressure, mmHg & 16,717 & $129.2 \pm 17.0$ & 111,354 & $135.2 \pm 18.6$ \\
\hline Diastolic blood pressure, $\mathrm{mmHg}$ & 16,644 & $77.1 \pm 10.2$ & 110,936 & $77.4 \pm 11.1$ \\
\hline Diabetic retinopathy & 6,355 & 17.7 & 36,681 & 8.7 \\
\hline Diabetic neuropathy & 17,649 & 27.2 & 116,746 & 37.2 \\
\hline Lipid metabolism disorders & 10,880 & 41.8 & 77,081 & 53.4 \\
\hline History of CV disease & 17,649 & 11.9 & 116,746 & 29.3 \\
\hline Coronary artery disease & 17,649 & 6.0 & 116,746 & 16.8 \\
\hline Peripheral arterial disease & 17,649 & 5.7 & 116,746 & 12.1 \\
\hline Heart failure & 17,649 & 2.9 & 116,746 & 12.4 \\
\hline Myocardial infarction & 17,649 & 2.7 & 116,746 & 7.4 \\
\hline Stroke & 17,649 & 2.9 & 116,746 & 7.5 \\
\hline PCl/Stent & 17,649 & 0.5 & 116,746 & 1.6 \\
\hline eGFR (CKD-EPI), mL/min/1.73 m² & 14,396 & $92.7 \pm 28.6$ & 106,692 & $68.3 \pm 27.1$ \\
\hline$\geq 60$ & 14,396 & 86.4 & 106,692 & 61.4 \\
\hline 45 to 59 & 14,396 & 6.3 & 106,692 & 16.1 \\
\hline 30 to 44 & 14,396 & 3.7 & 106,692 & 13.1 \\
\hline $15-29$ & 14,396 & 2.0 & 106,692 & 7.2 \\
\hline$<15$ & 14,396 & 1.6 & 106,692 & 2.2 \\
\hline \multicolumn{5}{|l|}{ Albuminuria determination } \\
\hline Albumin & 9,917 & 56.2 & 64,403 & 55.2 \\
\hline Albumin:Creatine ratio & 7,790 & 44.1 & 57,321 & 49.1 \\
\hline \multicolumn{5}{|l|}{ Albuminuria } \\
\hline Normoalbuminuria & 10,630 & 79.4 & 69,839 & 69.4 \\
\hline Microalbuminuria & 10,630 & 20.6 & 68,839 & 30.6 \\
\hline Macroalbuminuria & 9,939 & 5.1 & 64,472 & 9.1 \\
\hline Serum potassium, mEq/L, mean (SD) & 4,028 & $5.5 \pm 3.8$ & 27,115 & $5.3 \pm 3.6$ \\
\hline$<3.5 \mathrm{mEq} / \mathrm{L}$ & 4,028 & 5.0 & 27,115 & 5.4 \\
\hline $3.5-5.0 \mathrm{mEq} / \mathrm{L}$ & 4,028 & 78.5 & 27,115 & 78.7 \\
\hline$>5.0-5.5 \mathrm{mEq} / \mathrm{L}$ & 4,028 & 4.9 & 27,115 & 5.9 \\
\hline$>5.5 \mathrm{mEq} / \mathrm{L}$ & 4,028 & 11.6 & 27,115 & 10.0 \\
\hline \multicolumn{5}{|l|}{ RAS-blockers } \\
\hline ACEi & 17,649 & 10.2 & 116,746 & 22.9 \\
\hline ARBs & 16,388 & 6.2 & 116,746 & 14.0 \\
\hline $\mathrm{ACEi}+\mathrm{ARBs}^{*}$ & 17,649 & 0.7 & 116,746 & 1.3 \\
\hline MRA & 17,649 & 0.5 & 116,746 & 2.5 \\
\hline
\end{tabular}


Table 1 Patient characteristics (Continued)

\begin{tabular}{|c|c|c|c|c|}
\hline & \multicolumn{2}{|c|}{ Type 1 DM $(n=17,649)$} & \multicolumn{2}{|c|}{ Type 2 DM $(n=116,746)$} \\
\hline & $\mathrm{N}$ avail & Mean \pm SD or $\%$ & $\mathrm{~N}$ avail & Mean \pm SD or $\%$ \\
\hline \multicolumn{5}{|c|}{ GLP1-RA / SGLT-2i use } \\
\hline GLP-1 RA & 17,649 & 0.4 & 116,746 & 6.0 \\
\hline SGLT-2i & 17,649 & 1.0 & 116,746 & 9.0 \\
\hline
\end{tabular}

Legend: $A C E i$ angiotensin converting enzyme inhibitor; $A R B$ angiotensin receptor blocker; $B M I$ body mass index; CKD-EPI Chronic Kidney Disease Epidemiology Collaboration; SD standard deviation; DPP4 dipeptidyl peptidase-4; eGFR estimated glomerular filtration rate; GLP-1 glucagon-like peptide-1; HDL high density lipoprotein; LDL low density lipoprotein; MRAs mineralocorticoid receptor antagonists; $P C I$ percutaneous coronary intervention; SGLT-2, sodium-glucose transport protein-2; *Patients are part of ACEi and ARB rows as well; **Non-insulin antidiabetic therapy in T1DM needs to be interpreted with caution, as they may include patients with latent autoimmune diabetes in adults (LADA)

(recommendation class I, level of evidence A) [3]. In DIVE/DPV a regular ( $\geq 1 \mathrm{x} /$ year) determination of the eGFR (Fig. 2) was more frequent in type 2 (91.4\%) than in type 1 diabetes $(81.6 \%)$. The frequency of regular urinary albumin:creatinine determinations was comparable in type 1 (44.1\%) and type 2 diabetes (49.1\%). The proportion of patients who received at least one eGFR and one albumin:creatinine determination was comparable in type 1 (44.1\%) and type 2 diabetes (49.1\%).

\section{Glucose control}

Tight glucose control, targeting HbA1c $<7.0 \%$ (or $<53$ $\mathrm{mmol} / \mathrm{mol}$ ), is recommended by the ESC/EASD guideline [3] to decrease microvascular complications in patients with diabetes (recommendation class I, level of evidence A). In our dataset, $27.2 \%$ of patients with type 1 (Fig. 3) and $43.5 \%$ of patients with type 2 diabetes had an $\mathrm{HbA1c}$ that was in line with the above-mentioned recommendations.

Treatment with an SGLT-2i (empagliflozin, canagliflozin or dapagliflozin) is recommended as it is associated with a lower risk of renal endpoints [3] if eGFR is 30 to $<90 \mathrm{~mL} / \mathrm{min} / 1.73 \mathrm{~m}^{2}$ (recommendation class I, level of evidence B). In DIVE/DPV, treatment with SGLT-2i was not abundant with $1.5 \%$ of patients with type 1 and $8.7 \%$ of patients with type 2 diabetes receiving them (Fig. 4). As opposed to the guidelines, rates did not change for the patients within the eGFR range 30 to < $90 \mathrm{~mL} / \mathrm{min} / 1.73 \mathrm{~m}^{2}$. Treatment was generally initiated after the diagnosis of CKD. Use of SGLT-2 inhibitors was not abundant in type 1 diabetes and patients receiving them were characterized by a higher mean age (54.6 vs. 44.9 years), higher proportion of males (62.1 vs. $53.6 \%$ ), a higher BMI (28.9 vs. $\left.25.8 \mathrm{~kg} / \mathrm{m}^{2}\right)$ and a higher prevalence of CVD (25.3 vs. $11.8 \%$ ).

Treatment with the GLP1-RAs liraglutide and semaglutide should be considered [3] if eGFR is $>30 \mathrm{~mL} /$ $\mathrm{min} / 1.73 \mathrm{~m}^{2}$ as it is associated with a lower risk of renal endpoints (recommendation class IIa, level of evidence B). Treatment with GLP-1 RAs was not abundant with $0.6 \%$ of patients with type 1 and $5.3 \%$ of patients with type 2 diabetes receiving them (Fig. 5). Rates were comparable in patients with an eGFR > $30 \mathrm{~mL} / \mathrm{min} / 1.73$ $\mathrm{m}^{2}$, not in line with guideline recommendations. Treatment was again generally initiated after the diagnosis of CKD. Patients with type 1 diabetes receiving GLP-1RAs were characterized by a higher age ( 52.8 vs. 44.9 years), lower proportion of males (47.8 vs. $53.8 \%$ ), a higher BMI (34.8 vs. $25.8 \mathrm{~kg} / \mathrm{m}^{2}$ ) and a higher prevalence of CVD (26.9 vs. $11.9 \%)$

\section{Blood pressure control}

The guidelines [3] recommend that patients with hypertension and diabetes are treated in an individualized manner, SBP to $130 \mathrm{mmHg}$ and $<130 \mathrm{mmHg}$ if tolerated, but not $<120 \mathrm{mmHg}$. In patients $>65$ years the SBP goal lies within a range of 130-139 $\mathrm{mmHg}$ (recommendation class I, level of evidence A). In the DIVE/ DPV registry, hypertension control was $41.1 \%$ in type 1 and $67.7 \%$ in type 2 diabetes in patients $18-65$ years (Fig. 6). It was 62.4 and $68.4 \%$ in those $>65$ years, respectively.

RAAS blockers (ACEi or ARB) are recommended [3] for the treatment of hypertension in patients with diabetes mellitus, particularly in the presence of microalbuminuria, proteinuria or $\mathrm{LVH}$ (recommendation class I, level of evidence A). LVH was unfortunately not available in the current dataset. ACEi or ARB use was increased in patients with macroalbuminuria/proteinuria (40.9\%) and microalbuminuria (24.0\%) compared with the total population of patients with type 1 diabetes (15.3\%) (Fig. 7). The same was true for patients with type 2 diabetes ( $47.7 \%$ and 39.0 vs. $34.6 \%$ ). ACEi/ARB use was also higher in patients with a GFR $<60 \mathrm{~mL} / \mathrm{min} /$ $1.73 \mathrm{~m}^{2}$ (35.9\% type $1 ; 41.0 \%$ type 2 diabetes) than in patients with a GFR $\geq 60 \mathrm{~mL} / \mathrm{min} / 1.73 \mathrm{~m}^{2}(14.3$ and $33.5 \%$, respectively). ACEi/ARB use was also higher in patients with CKD (26.2 \% type 1; $39.5 \%$ type 2 diabetes) than in patients without (12.7 and $31.7 \%$, respectively).

\section{Discussion}

This database analysis shows that (1) about every other patient with diabetes is screened for the presence of CKD annually; (2) less than half of patients achieve a 
target $\mathrm{HbA} 1 \mathrm{c}$ of $<7.0 \%$ (or $<53 \mathrm{mmol} / \mathrm{mol}$ ); recommended use of SGLT-2i and GLP1-RA is well below $10 \%$; (3) hypertension is controlled in about two-thirds of patients with lower rates depending on age and respective SBP thresholds; RAAS blockers are used in about half of the patients. Taken together there appears to be room for improvement with respect to the renal aspects of diabetes care to prevent kidney-associated morbidity and mortality. It is important to understand guideline compliance because adherence to treatment guidelines is associated with improved clinical outcomes in patients with type 2 diabetes, better glycaemic and blood pressure control, and it has the potential to reduce the risk of developing CKD/ESRD through comprehensive patient assessment $[10,11]$.

\section{Chronic Kidney Disease Screening}

Renal involvement in diabetes is common and CKD significantly increases the risk of atrial fibrillation in patients with diabetes [12]. It is essential, therefore, that kidney involvement is detected as early as possible. The ESC/EASD recommendations to screen patients annually for kidney disease using eGFR and UACR has also been recommended by the 2020 American Diabetes Association (ADA) [4] and the 2013 Kidney Disease: Improving Global Outcomes (KDIGO) Clinical Practice Guideline [13]. The recent 2020 KDIGO guidelines [14] supports this approach in a more general sense as they recommend multifactorial diabetes management with yearly assessment of urine albumin excretion and eGFR, but refer to primary care and endocrinology society guidelines for further details.

Only about half of the patients with diabetes, irrespective of diabetes type, were screened annually in DIVE/DPV, which appears low. The data are, however, not far off from those of Hagnas et al., [15] which investigated CKD-screening in Finnish primary healthcare, where $60.2 \%$ of 5,112 patients with type 2 diabetes were regularly screened for both eGFR and albuminuria. An Australian cross-sectional study [16] found that among 90,550 patients with type 2 diabetes, only 44,394 (49.0\%) were appropriately screened or monitored. Rates in the present study, therefore, are plausible.

There are a number of potential reasons for this low screening rate. First, it may be the result of partial guideline inconsistencies. For example, the 2020 ADA guidelines [4] recommend only to screen for CKD in type 1 diabetes if diabetes duration is $\geq 5$ years. This criterion is not met for at least some of the patients in the current dataset with a median diabetes duration of 11.9 years and an interquartile range of 2.7 to 25.0 years. Secondly, as multiple determinations of urinary albumin (at least two tests out of three need to be positive to arrive at a diagnosis of microalbuminuria) are necessary, the efforts for screening may be perceived to be high. Conversely, albuminuria tests are sometimes regarded as unreliable, especially if only performed once. Thirdly, not every physician's office is able to collect urinary samples, which may appear unhygienic and, thus, not desirable. As a potential limitation, we did not explore whether a twice-annual monitoring of kidney function is actually performed in patients with advanced disease (urinary albumin $>30 \mathrm{mg} / \mathrm{g}$ creatinine and/or eGFR $<60 \mathrm{~mL} /$ $\mathrm{min} / 1.73 \mathrm{~m}^{2}$ ). Some patients counted as screened in our analysis, would not be classified based on a requirement for two annual investigations as suggested by the ADA.

Finally, only about half of all patients in our database were screened based on both urinary albumin and creatinine. As opposed to the majority of guidelines, a determination of urinary albumin without normalization to creatinine appears to be frequent in clinical practice. This is of concern as a simple urinary dipstick test has a lower sensitivity and higher false-discovery rate compared to UACR-based screening $[17,18]$. It has been previously described that there is no standardised method of collection and measurement of urinary albumin and creatinine and there are concerns about test reliability, intra-individual variability based on body position, activity and temperature $[19,20]$.

\section{Blood glucose control and treatment}

Only $43.5 \%$ of patients with type 2 diabetes reached the ESC/EASD [3] recommended HbA1c treatment target of $<7.0 \%$. Glucose control in type 2 diabetes is generally a matter of debate and a patient-centred approach suggests that individual blood glucose targets should be pursued. Variables that influence the actual HbA1c target are patient age, hypoglycaemic risk, and the comorbidity and comedication burden of patients. While the 2020 ADA guidelines recommend no specific treatment target [4], $2020 \mathrm{KDIGO}$ recommends an individualised HbA1c target range between $<6.5 \%$ and $<8.0 \%$ with higher targets tolerated for patients with present/severe macrovascular complications, many comorbidities and high hypoglycaemia risk [14]. Moreover, KDIGO recommends looser $\mathrm{HbA1c}$ targets in patients with severe CKD, which is at odds with the ESC/EASD recommendation [3]. This is in principal alignment with the recent German recommendations which pursue a corridor of $6.5-7.5 \%$ to prevent CKD with the upper values recommended for patients with macroangiopathy. To prevent progression, an HbA1c value of $7 \%$ or less is requested [18].

Less than $10 \%$ of patients with type 2 diabetes received the two treatment options (SGLT-2i and/or GLP1-RAs) recommended for the reduction of renal endpoints by ESC/EASD [3]. The 2020 ADA guidelines [4] is slightly more specific than the ESC/EASD guidelines as to the use of SGLT-2i [3]. It recommends 
SGLT-2i use in those patients with type 2 diabetes with an eGFR $\geq 30 \mathrm{~mL} / \mathrm{min} / 1.73 \mathrm{~m}^{2}$ and urinary albumin $>$ $30 \mathrm{mg} / \mathrm{g}$ creatinine, particularly in those with urinary albumin $>300 \mathrm{mg} / \mathrm{g}$ creatinine. KDIGO 2020 recommends SGLT-2i in patients with an eGFR $\geq 30 \mathrm{~mL} / \mathrm{min} / 1.73 \mathrm{~m}^{2}$ on the basis of metformin and GLP-1 RAs or in patients who are unable to tolerate these aforementioned medications [14]. Actual rates in DIVE/DPV were, however, very low with $\sim 9 \%$ and $\sim 6 \%$ of the patients with type 2 diabetes receiving SGLT-2i and GLP-1 Ras, respectively. These numbers have to be interpreted in light of their more recent market introduction, limitations by the approved indication (start of treatment until eGFR $\geq 60$, stop treatment from eGFR $<45 \mathrm{ml} / \mathrm{min} / 1.73 \mathrm{~m}^{2}$ ), the only recent recommendation in guidelines (using the 2020 guidelines as a reference) and the lack of documentation for potential reasons for their non-use.

About $27.2 \%$ of patients with type 1 diabetes in DIVE/ DPV reached a target HbA1c $<7.0$ and $1.5 \%$ (SGLT-2i)/ $0.6 \%$ (GLP-1 RAs) received guideline-preferred antidiabetic drugs as defined by the ESC/EASD [3]. While HbA1c treatment targets are no less stringent in type 1 than type 2 diabetes, the value of SGLT-2i/GLP-1 RAs in type 1 diabetes is less well documented. In 2019, the European Medicines Agency (EMA) approved a first SGLT-2i and a first dual SGLT-1/-2i to improve glycaemic control, as an adjunctive treatment to insulin in people with type 1 diabetes and a $\mathrm{BMI} \geq 27 \mathrm{~kg} / \mathrm{m}^{2}$ [21]. Of note, these are not approved for patients with type 1 diabetes by the Food and Drug Administration (FDA). No GLP1-RAs are registered for use in type 1 diabetes and neither agency recommends their use in patients with CKD. As such, the low use rate in type 1 diabetes is not surprising, even more so as non-insulin antidiabetic treatment in type 1 diabetes is rare anyway.

\section{Hypertension control and treatment}

Blood pressure was controlled for $41.1-68.4 \%$ in patients in DIVE/DPV depending on diabetes type and age for which different targets have been defined [3]. These findings are supported by another German study, which showed that blood pressure in patients with diabetes is insufficiently managed [22]. The ESC/ EASD guidelines are very specific in recommending SBP to $130 \mathrm{mmHg}$ and $<130 \mathrm{mmHg}$ if tolerated, but not $<120 \mathrm{mmHg}$ in patients between 18 and 65 years and $130-139 \mathrm{mmHg}$ in patients $>65$ years. The 2020 ADA and KDIGO $[4,14]$ give no specific recommendations as to the target blood pressure pursued, but rather confine their recommendation to the use of RAAS-blocking agents (ACEI or ARB) like the ESC/ EASD. We documented ACEi use in $24.0 \%$ (type 1 diabetes) and $39.9 \%$ (type 2 diabetes) in patients with microalbuminuria with higher rates seen in patients with macroalbuminuria/proteinuria (40.9\%/47.7\%) which is below the rates observed for patients with type 2 diabetes in a Finnish study (57.0\%) [15]. KDIGO also recommends titration of the RAASblocker to the highest approved dose that is tolerated. The dose (and the presence of LVH) was not documented in our dataset, which prevents us from judging adequacy of treatment in this respect.

\section{Areas in need of future study or ongoing research}

Guidelines conform in demanding regular screening for CKD in patients with diabetes, tight glucose control with the use of SGLT-2i (and GLP-1 RAs), and tight blood pressure control using ACEi/ARBs in those with hypertension and any degree of albuminuria. Inconsistencies are observed when looking at specific recommendations. The degree of translation into clinical practice has room for further improvement, but is somewhat uncertain because of the lack of specific data on the presence of drug contraindications, drug interactions and concomitant disease.

Based on our analysis we believe that (1) partial inconsistency between guidelines with respect to screening and treatment efforts prevents clinical practice to catch up and fully comply with these recommendations. (2) Further research is needed into the use of antidiabetic drugs and their potential benefits in CKD patients with type 2 and potentially even more so in type 1 diabetes. (3) Clear-cut recommendations on the use of antihypertensive and renoprotective drugs is needed. These drugs are widely used irrespective of the presence of albuminuria, but need to be consistently used in those with renal disease. (4) Beneficial drugs are usually not titrated to a maximally tolerated and effective dose resulting in suboptimal effects on renal and overall cardiovascular endpoints. Conversely, over-diagnosis and over-treatment may be deleterious to patients and society from a health and cost perspective and we encourage individual treatment decisions for each patient to maximise the benefits of current (and future) diagnostic and therapeutic treatment options.

\section{Limitations}

The main limitation is the retrospective nature of this study, using data from a registry. However, due to the number of patients enrolled in the registry, we can be confident that the data provides a true reflection of diabetes patients in Germany. In addition, the data quality is very much dependent on the information included in the registry by the patient's prescribing physician. There may be reasons for justified noncompliance to treatment guidelines but this information is not captured in the registry. Finally, this is a 
single-country study - based on German data - and may not reflect guideline compliance in other countries.

\section{Conclusions}

The data indicate that there is room for improvement in the care of patients with diabetes with respect to renal disease diagnosis and treatment. While specific and potentially clinically justified reasons for non-compliance exist, the data may serve well for a critical appraisal of clinical practice decisions.

\section{Acknowledgements}

We thank all participating centres of the DPV and DIVE initiatives. Special thanks to A. Hungele and R. Ranz for support and the development of the DPV documentation software, K. Fink and E. Bollow for the DPV data management (all clinical data managers, Ulm University).

\section{Authors' contributions}

$\mathrm{EH}, \mathrm{SF}, \mathrm{CHJH}, \mathrm{MF}$, and TD contributed to the data collection. PB and SL designed the analysis, drafted the manuscript and created figures. SL and RWH were responsible for the statistical analyses. EH, SF, CHJH, MF, JS, TD, IB and RWH contributed to the discussion and reviewed/edited the manuscript. RWH had full access to all the data in the study and takes responsibility for the integrity of the data and the accuracy of the data analysis. All authors approved the final manuscript to be submitted.

\section{Funding}

The DPV registry is supported by the German Diabetes Society (DDG) and the German Centre for Diabetes Research (DZD, grant number 82DZD14A02). The DIVE registry received funding from Abbott, AstraZeneca, Bayer, Boehringer and Sanofi. This specific analysis was funded by Bayer. Funders were not involved in the analysis and interpretation of data, the writing of the report or the decision to submit the article for publication.

\section{Availability of data and materials}

The data that support the findings of this study are available on reasonable request from the corresponding author. The data are not publicly available due to privacy or ethical restrictions.

\section{Declarations}

\section{Ethics approval and consent to participate}

The DPV initiative, which was established in 1995, was approved by the ethics committee of the University of UIm, and data collection was approved by local review boards. The DIVE registry was established in Germany in 2011. The protocol was approved by the ethics committee of the Medical School of Hannover, and all patients included in the DIVE registry provided written informed consent. All methods were carried out in accordance with relevant guidelines and regulations.

\section{Consent for publication}

Not applicable.

\section{Competing interests}

JS and TD report grants and personal fees from Abbott, AstraZeneca, and Sanofi, outside the submitted work. PB reports to have received research support from the funders of DIVE. SL, GVM, EH, SF, CHJH, MF and RWH have no competing interests to disclose.

\section{Author details}

'Institute for Pharmacology and Preventive Medicine, Bahnhofstrasse 20, 49661 Cloppenburg, Germany. ${ }^{2}$ Institute for Epidemiology and Medical Biometry, ZIBMT, University of UIm, UIm, Germany. ${ }^{3}$ German Center for Diabetes Research (DZD), Munich-Neuherberg, Germany. ${ }^{4}$ Specialized Diabetes Practice Dres. Hess, Worms, Germany. ${ }^{5}$ Medical Clinic, SRH Clinic Sigmaringen, Pfullendorf, Germany. ${ }^{6}$ Specialized Diabetes Practice Viersen, Viersen, Germany. ${ }^{7}$ Protestant Hospital, Oberhausen, Germany. ${ }^{8}$ DAZB
(German Angiology Center Brandenburg/Berlin), Medical School Brandenburg (MHB) \& Faculty of Health Science FGW, Brandenburg, Germany. ${ }^{9}$ European Foundation for Vascular Medicine (EFVM), Brandenburg Havel, Germany. ${ }^{10}$ Kinderkrankenhaus auf der Bult, Diabetes Centre for Children and Adolescents, Hannover, Germany. ${ }^{11}$ Division of Endocrinology and Diabetology, Department of Medicine II, Medical Center, Faculty of Medicine, University of Freiburg, Freiburg, Germany.

Received: 18 February 2021 Accepted: 7 May 2021

Published online: 19 May 2021

\section{References}

1. Levey AS, de Jong PE, Coresh J, El Nahas M, Astor BC, Matsushita K, Gansevoort RT, Kasiske BL, Eckardt KU: The definition, classification, and prognosis of chronic kidney disease: a KDIGO Controversies Conference report. Kidney Int 2011, 80(1):17-28.

2. KDIGO 2012: Clinical Practice Guideline for the Evaluation and Management of Chronic Kidney Disease: Chap. 1: Definition and classification of CKD. Kidney Int Suppl 2013, 3:19-62.

3. Cosentino F, Grant PJ, Aboyans V, Bailey CJ, Ceriello A, Delgado V, Federici M, Filippatos G, Grobbee DE, Hansen TB et al: 2019 ESC Guidelines on diabetes, pre-diabetes, and cardiovascular diseases developed in collaboration with the EASD. Eur Heart J 2020, 41(2):255-323.

4. American Diabetes A: 11. Microvascular Complications and Foot Care: Standards of Medical Care in Diabetes-2020. Diabetes Care 2020, 43(Suppl 1):S135-S151.

5. Bramlage $P$, Lanzinger S, Hess E, Fahrner S, Heyer CHJ, Friebe M, Buschmann I, Danne T, Holl RW, Seufert J: Renal function deterioration in adult patients with type-2 diabetes. BMC Nephrol 2020, 21(1):312.

6. Bramlage $P$, Lanzinger $S$, van Mark $G$, Hess $E$, Fahrner $S$, Heyer $C H J$, Friebe M, Seufert J, Danne T, Holl RW: Patient and disease characteristics of type-2 diabetes patients with or without chronic kidney disease: an analysis of the German DPV and DIVE databases. Cardiovasc Diabetol 2019, 18(1):33.

7. Danne T, Kaltheuner M, Koch A, Ernst S, Rathmann W, Russmann HJ, Bramlage P, Studiengruppe D: ["Dlabetes Versorgungs-Evaluation" (DIVE)--a national quality assurance initiative at physicians providing care for patients with diabetes]. Dtsch Med Wochenschr 2013, 138(18):934-939.

8. Sandig D, Grimsmann J, Reinauer C, Melmer A, Zimny S, Muller-Korbsch M, Forestier N, Zeyfang A, Bramlage P, Danne T et al: Continuous Glucose Monitoring in Adults with Type 1 Diabetes: Real-World Data from the German/Austrian Prospective Diabetes Follow-Up Registry. Diabetes Technol Ther 2020, 22(8):602-612.

9. Biester T, Grimsmann JM, Heidtmann B, Rami-Merhar B, Ermer U, Wolf J, Freff M, Karges B, Agena D, Bramlage P et al: Intermittently scanned glucose values for continuous monitoring: Cross-sectional analysis of glyceamic control and hypoglycaemia in 1809 children and adolescents with type 1 diabetes. Diabetes Technol Ther 2020.

10. Lu J, Zhao W, Chen T, Xu Z, Sun X, Xie H, An Y, Zeng C, Hu G, Xie G et al: Influence of guideline adherence and parameter control on the clinical outcomes in patients with diabetic nephropathy. BMJ Open Diabetes Res Care 2020, 8(1).

11. Imai C, Li L, Hardie RA, Georgiou A: Adherence to guideline-recommended $\mathrm{HbA1c}$ testing frequency and better outcomes in patients with type 2 diabetes: a 5-year retrospective cohort study in Australian general practice. BMJ Qual Saf 2021.

12. Heo NJ, Rhee SY, Waalen J, Steinhubl S: Chronic kidney disease and undiagnosed atrial fibrillation in individuals with diabetes. Cardiovasc Diabetol 2020, 19(1):157.

13. Kidney Disease: Improving Global Outcomes (KDIGO) CKD Work Group: KDIGO 2012 Clinical Practice Guideline for the evaluation and management of chronic kidney disease. Kidney Int Suppl 2013, 3:1-150.

14. Kidney Disease: Improving Global Outcomes Diabetes Work G: KDIGO 2020 Clinical Practice Guideline for Diabetes Management in Chronic Kidney Disease. Kidney Int 2020, 98(4S):S1-S115.

15. Hagnas $M$, Sundqvist $H$, Jokelainen J, Tumminia A, Vinciguerra F, Loreto $C$, Frittitta L, Russo GT, Mikkola I: The prevalence of chronic kidney disease and screening of renal function in type 2 diabetic patients in Finnish primary healthcare. Prim Care Diabetes 2020, 14(6):639-644.

16. Manski-Nankervis JE, Thuraisingam S, Lau P, Blackberry I, Sluggett JK, llomaki $J$, Bell JS, Furler J: Screening and diagnosis of chronic kidney disease in 
people with type 2 diabetes attending Australian general practice. Aust J Prim Health 2018, 24(3):280-286.

17. Park Jl, Baek H, Kim BR, Jung HH: Comparison of urine dipstick and albumin: creatinine ratio for chronic kidney disease screening: A population-based study. PLoS One 2017, 12(2):e0171106.

18. Merker L, Bautsch BW, Ebert T, Guthoff M, Isermann B: [Nephropathy in Diabetes]. Diabetologie 2020, 15((Suppl. 1)):S170-S174.

19. Saunders MR, Cifu A, Vela M: Screening for Chronic Kidney Disease. JAMA 2015, 314(6):615-616.

20. Miller WG, Bruns DE, Hortin GL, Sandberg S, Aakre KM, McQueen MJ, Itoh Y, Lieske JC, Seccombe DW, Jones G et al: Current issues in measurement and reporting of urinary albumin excretion. Clin Chem 2009, 55(1):24-38.

21. Gillard P, Schnell O, Groop PH: The nephrological perspective on SGLT-2 inhibitors in type 1 diabetes. Diabetes Res Clin Pract 2020, 170:108462.

22. Rückert IM, Schunk M, Holle R, Schipf S, Völzke H, Kluttig A, Greiser KH, Berger K, Müller G, Ellert U et al: Blood pressure and lipid management fall far short in persons with type 2 diabetes: results from the DIAB-CORE Consortium including six German population-based studies. Cardiovasc Diabetol 2012, 11:50.

\section{Publisher's Note}

Springer Nature remains neutral with regard to jurisdictional claims in published maps and institutional affiliations.

Ready to submit your research? Choose BMC and benefit from:

- fast, convenient online submission

- thorough peer review by experienced researchers in your field

- rapid publication on acceptance

- support for research data, including large and complex data types

- gold Open Access which fosters wider collaboration and increased citations

- maximum visibility for your research: over $100 \mathrm{M}$ website views per year

At $\mathrm{BMC}$, research is always in progress.

Learn more biomedcentral.com/submissions 